\title{
Intoxicação experimental por Baccharis coridifolia (Compositae) em bovinos ${ }^{1}$
}

\author{
Mary Suzan Varaschin ${ }^{2}$, Claudio S.L. Barros ${ }^{3}$ e Bruce B. Jarvis ${ }^{4}$
}

\begin{abstract}
Varaschin M.S., Barros C.S.L. \& Jarvis B.B. 1998. [Experimental poisoning by Baccharis coridifolia (Compositae) in cattle.] Intoxicação experimental por Baccharis coridifolia (Compositae) em bovinos. Pesquisa Veterinária Brasileira 18(2):69-74. Depto Patologia, Universidade Federal de Santa Maria, Santa Maria, RS 97119-900, Brazil.

Thirteen calves were fed single doses varying from 0.5 to $5 \mathrm{~g} / \mathrm{kg}$ of either freshly harvested or dried Baccharis coridifolia. One calf was fed 4 daily doses of $0,5 \mathrm{~g} / \mathrm{kg}$ of the dried plant. Two calves did not receive the plant and served as controls. The plant material was harvested each month from July 1991 to May 1992 and then in March 1993, and was analysed for its content in macrocyclic trichothecenes. When in flower the female and male plant specimens were both analysed and fed separately to calves. The levels of macrocyclic trichothecenes and their glucosides were much higher in the flowering female plants compared with the levels observed in those plants not in flower and in the flowering male plants. Ten calves either died or were euthanatized due to the toxicosis. Two calves fed the female flowering plant got sick and died, while 3 calves fed the flowering male plant did not develop the toxicosis. Clinical signs in the poisoned calves were anorexia, dehydration, ruminal atony, abdominal distension and pain, liquid diarrhea, dry muzzle, imbalance in the hindlimbs and sternal recumbency. Main pathological findings included necrosis of the gastrointestinal tube, particularly in the forestomachs and in the lymphoid tissues except for the thymus. The latter suggests an effect upon the B cells of the lymphoid tissue. The distribution of the lesions in the digestive and lymphoid systems was sistematically determined. It is concluded that the macrocyclic trichothecenes present in the plant account for the lesions observed in the toxicosis and that the female flowering plant is substantially more toxic than the flowering male plants or plants not in flower. This difference in toxicity is due to the difference in macrocyclic trichothecenes contents.
\end{abstract}

INDEX TERMS: Poisonous plants, experimental poisoning, Baccharis coridifolia, Compositae, cattle diseases, pathology.

RESUMO.- Treze terneiros receberam Baccharis coridifolia recémcolhida ou dessecada, em doses únicas que variaram entre 0,5 e $5 \mathrm{~g} / \mathrm{kg}$. Um terneiro recebeu quatro administrações diárias de $0,5 \mathrm{~g} / \mathrm{kg}$ da planta dessecada. Dois terneiros não receberam a planta e serviram como controles. A planta foi colhida mensal-

\footnotetext{
${ }^{1}$ Aceito para publicação em 26 de fevereiro de 1998.

Parte da Dissertação de Mestrado do primeiro autor, apresentada ao Curso de Pós-Graduação em Medicina Veterinária, área de concentração em Patologia Veterinária da Universidade Federal de Santa Maria (UFSM), em 5 de fevereiro de 1996. Trabalho financiado pela FAPERGS, Processo 93/2929.2.

${ }^{2}$ Departamento de Patologia, Universidade de Alfenas, Rodovia MG 179, Km 0, Caixa Postal 23, Alfenas, MG 37130-000.

${ }^{3}$ Departamento de Patologia, UFSM, Santa Maria, RS 97119-900.

${ }^{4}$ Department of Chemistry and Biochemistry, University of Maryland, College Park, Estados Unidos.
}

mente de julho de 1991 a maio de 1992 e em março de 1993, e foi analisada para seu conteúdo em tricotecenos macrocíclicos. Quando em floração, as amostras dos espécimes macho e fêmea da planta foram analisadas e administradas aos terneiros separadamente. Os níveis de tricotecenos macrocíclicos e seus glicosídeos foram muito maiores nas plantas fêmeas em floração do que os níveis observados nas plantas não em floração e nas plantas machos em floração. Dez bovinos morreram espontaneamente ou foram sacrificados devido à toxicose. Dois terneiros que receberam a planta fêmea em floração, adoeceram e morreram, enquanto que três terneiros que receberam a planta macho em floração não adoeceram. Os sinais clínicos nos terneiros intoxicados foram anorexia, desidratação, atonia ruminal, tensão e dores abdominais, diarréia líquida, focinho seco, instabilidade dos membros posteriores e decúbito esternal. Os achados patológicos incluiram lesões necróticas no tubo gastrintestinal, particularmente nos pré-estômagos, e nos tecidos linfóides com 
Mary S. Varaschin, Claudio S.L. Barros e Bruce B. Jarvis

exceção do timo. Esse último achado sugere um efeito sobre as células B do tecido linfóide. A distribuição das lesões nos sistemas digestivo e linfóide foi sistematicamente determinada. Conclui-se que os tricotecenos macrocíclicos presentes na planta são responsáveis pelas lesões observadas na toxicose e que a planta fêmea em floração é substâncialmente mais tóxica que a planta macho em floração ou das plantas que não estão em floração. Essa diferença em toxicidade é devida à diferença no conteúdo de tricotecenos macrocíclicos.

TERMOS DE INDEXAÇÃO: Plantas tóxicas, intoxicação experimental, Baccharis coridifolia, Compositae, doenças de bovinos, patologia.

\section{INTRODUÇÃO}

Baccharis coridifolia ("mio-mio") é uma das plantas tóxicas mais importantes do sul do Brasil, ocorrendo também em partes do estado de São Paulo (Occhioni 1944). A intoxicação espontânea é mais frequente em bovinos, ocorre ocasionalmente em ovinos (Barros 1993) e mais raramente em equinos (Méndez 1995). Tem sido reproduzida em bovinos (Tokarnia \& Döbereiner 1975), ovinos (Tokarnia \& Döbereiner 1976), coelhos (Döbereiner et al. 1976, Rodrigues \& Tokarnia 1995) e equinos (Costa et al. 1995).

Em bovinos, as principais lesões ocorrem no trato gastrintestinal e consistem de degeneração, necrose e desprendimento do epitélio de revestimento dos pré-estômagos. Há citações de lesões necróticas no tecido linfóide (Barros 1993).Tricotecenos macrocíclicos (TMs) foram determinados como o princípio ativo de B. coridifolia (Busam \& Habermehl 1982). Essas substâncias são produzidas por fungos que crescem no solo e são absorvidas pela planta. Variações na toxidez entre os períodos de brotação e floração e entre os espécimes macho e fềmea de $B$. coridifolia foram relatadas (Tokarnia \& Döbereiner 1975 , Rodrigues \& Tokarnia, 1995) e o princípio tóxico foi demonstrado ocorrer em maior concentração nos espécimes fêmeas da planta (Jarvis et al. 1988). O presente experimento foi conduzido para avaliar a morfologia e distribuição das lesões no epitélio do tubo gastrintestinal e no tecido linfóide na intoxicação por $B$. coridifolia $e$ a variação no conteúdo de princípio ativo e na toxidez de $B$. coridifolia, em relação à epoca do ano e ao sexo da planta.

\section{MATERIAL E MÉTODOS}

Onze colheitas de $B$. coridifolia foram realizadas mensalmente entre julho de 1991 e maio de 1992. Uma colheita adicional foi realizada em março de 1993 (Quadro 1). O local das colheitas foi sempre o mesmo e fica à margem esquerda do $\mathrm{Km} 214$ da rodovia BR 287, a 17 km de Santa Maria em direção a São Pedro do Sul. Amostras de 50 gramas de cada colheita foram secadas a sombra e analisadas para presença de tricotecenos macrocíclicos (TMs). As análises foram realizadas de duas maneiras: i) os extratos foram hidrolisados e analisados para verrucarol por cromatografia de gás-espectofotometria de massa, que dá a concentração total de TMs na amostra e ii) analisados para identificação qualitativa de TMs individuais por cromotografia líquida em alta pressão. Os detalhes dessa metodologia já foram publicados (Jarvis et al. 1996).

Foram utilizados 16 bovinos machos, com idade entre 3 e 16 meses (Quadro 2). Os animais foram colocados em baias individuais de alvenaria, alimentados com feno de alfafa, ração e água à vontade.
Quadro 1. Intoxicação experimental por Baccharis coridifolia (Compositae) em bovinos. Datas de colheita e sexo da planta usada no experimento

\begin{tabular}{|c|c|c|}
\hline $\begin{array}{c}\text { Identificação } \\
\text { amostra }\end{array}$ & Data da colheita & Sexo da planta \\
\hline $7 / 91^{a}$ & Julho 1991 & Não determinado \\
\hline $8 / 91^{a}$ & Agosto 1991 & Não determinado \\
\hline $9 / 91$ & Setembro 1991 & Não determinado \\
\hline $10 / 91$ & Outubro 1991 & Não determinado \\
\hline $11 / 91$ & Novembro 1991 & Não determinado \\
\hline $12 / 91$ & Dezembro 1991 & Não determinado \\
\hline $1 / 91$ & Janeiro 1992 & Não determinado \\
\hline $2 / 92 / a^{b}$ & Fevereiro 1992 & Macho \\
\hline $2 / 92 / b^{b}$ & Fevereiro 1992 & Fêmea \\
\hline $3 / 92 / a$ & Março 1992 & Macho \\
\hline $3 / 92 / b$ & Março 1992 & Fêmea \\
\hline 4/92/a & Abril 1992 & Macho \\
\hline $4 / 92 / \mathrm{b}^{\mathrm{b}}$ & Abril 1992 & Fêmea \\
\hline $5 / 92 / a$ & Maio 1992 & Macho \\
\hline $5 / 92 / b$ & Maio 1992 & Fêmea \\
\hline $3 / 93 / a^{b}$ & Março 1993 & Macho \\
\hline $3 / 93 / b^{b}$ & Março 1993 & Fêmea \\
\hline
\end{tabular}

a Análise química não realizada.

b Amostra não administrada aos bovinos.

A planta foi administrada verde, imediatamente após a colheita, ou, ocasionalmente, após ser secada à sombra. O tipo de planta administrada, as doses e o número de administrações constam do Quadro 2. As quantidades de planta seca administrada aos bovinos estão expressadas em seus pesos correspondentes em planta verde. A proporção planta seca para planta verde para $B$. coridifolia foi estabelecida como 1:4 na brotação e 1:3 na floração em termos de peso (Tokarnia \& Döbereiner 1975); porém a planta perde aproximadamente a metade de sua toxidez no processo de dessecação.

Os bovinos foram examinados clinicamente antes e após receberem a planta.Todos os bovinos que morreram espontaneamente ou foram sacrificados, inclusive os controles, foram necropsiados. $\mathrm{O}$ material colhido na necropsia foi consistentemente o mesmo e foi processado da mesma maneira em todos os casos. Todo o material colhido para histologia foi fixado em formol neutro a $10 \%$ e processado rotineiramente para histopatologia. Para análise das alterações no sistema linfóide foram colhidos 12 linfonodos, timo, baço, acúmulos linfóides associados ao intestino, medula óssea ( $3^{\text {a }}$ costela direita) e acúmulos linfóides peribrônquicos. Os linfonodos consistentemente examinados foram abdominal dorsal, axilar, bronquial, esplênico, ilíaco interno, intercostal, mandibular, mediastínico caudal, mesentérico, poplíteo, pré-escapular e renal. Foram colhidos ainda fragmentos de diversos partes do tubo gastrintestinal, do fígado, rim, encéfalo e das adrenais. Para a análise das alterações epiteliais do tubo digestivo foram colhidos fragmentos de rúmen (saco dorsal, saco ventral, saco cego caudal dorsal, saco cego caudal ventral e pilar anterior), retículo, omaso, abomaso (regiões fúndica e pilórica), duodeno, entrada íleo cecal, cólon proximal, cólon espiral, ceco e reto.

\section{RESULTADOS}

Os resultados das análise químicas realizadas nas amostras de $B$. coridifolia já foram publicadas (Jarvis et al. 1996) e encontram-se resumidas no Quadro 3. De modo geral, observou-se maior con- 
Quadro 2. Intoxicação experimental por Baccharis coridifolia (Compositae) em bovinos

\begin{tabular}{|c|c|c|c|c|c|c|c|c|c|}
\hline \multirow{2}{*}{$\begin{array}{c}\text { Bovino } \\
n^{\circ}\end{array}$} & \multirow{2}{*}{$\begin{array}{l}\text { Peso } \\
\text { (kg) }\end{array}$} & \multirow{2}{*}{$\begin{array}{c}\text { Idade } \\
\text { (meses) }\end{array}$} & \multirow{2}{*}{$\begin{array}{l}\text { Identificação } \\
\text { da planta } \\
\text { administrada }\end{array}$} & \multirow{2}{*}{$\begin{array}{c}\text { Sexo da } \\
\text { planta }\end{array}$} & \multirow{2}{*}{$\begin{array}{c}\text { Quantidade } \\
\text { da planta } \\
\text { administrada } \\
(\mathrm{g} / \mathrm{kg})\end{array}$} & \multirow{2}{*}{$\begin{array}{l}\text { Dose total } \\
(\mathrm{g})\end{array}$} & \multicolumn{2}{|c|}{ Sinais clínicos } & \multirow{2}{*}{$\begin{array}{l}\text { Desfecho da } \\
\text { intoxicação }\end{array}$} \\
\hline & & & & & & & $\begin{array}{c}\text { Início após } \\
\text { administração } \\
\text { da planta }\end{array}$ & $\begin{array}{c}\text { Duração } \\
\text { (h) }\end{array}$ & \\
\hline 01 & 112 & 16 & $7 / 91$ & $\mathrm{Nd}^{\mathrm{a}}$ & 5 & 560 & 13 & 8 & Morreu \\
\hline 02 & 51 & 5 & $7 / 91$ & $\mathrm{Nd}$ & 5 & 255 & 13 & 8 & Sacrificado \\
\hline 03 & 50 & 4 & $8 / 91$ & $\mathrm{Nd}$ & 3 & 150 & $?$ & Aprox. 6 & Morreu \\
\hline 04 & 160 & 9 & $9 / 91$ & $\mathrm{Nd}$ & 2 & 320 & 15 & 14 & $\begin{array}{c}\text { Adoeceu mas } \\
\text { sobreviveu }\end{array}$ \\
\hline 05 & 95 & 8 & $10 / 91$ & $\mathrm{Nd}$ & 3 & 285 & 13 & 35 & Morreu \\
\hline 06 & 115 & 8 & $11 / 91$ & $\mathrm{Nd}$ & 3 & 345 & 14 & 2 & Morreu \\
\hline $07^{b}$ & 63 & 4 & $7 / 91^{\mathrm{c}}$ & $\mathrm{Nd}$ & 0,5 & 31,5 & $?$ & Aprox. 3 & Sacrificado \\
\hline 08 & 40 & 3 & $12 / 91$ & $\mathrm{Nd}$ & 3 & 120 & $?$ & Aprox. 80 & Morreu \\
\hline 09 & 70 & 6 & $1 / 92$ & $\mathrm{Nd}$ & 3 & 210 & 15 & 2 & Morreu \\
\hline 10 & 94 & 3 & $3 / 92 a$ & M & 1,5 & 141 & - & - & Não adoeceu \\
\hline 11 & 83 & 3 & $3 / 92 b$ & $\mathrm{~F}$ & 1,5 & 124,5 & $?$ & Aprox. 2 & Morreu \\
\hline 12 & 56 & 2 & $4 / 92 a^{c}$ & M & 0,5 & 28 & - & - & Não adoeceu \\
\hline 13 & 60 & 3 & $5 / 92 b$ & $\mathrm{~F}$ & 3 & 180 & 15 & 11 & Morreu \\
\hline $14^{\mathrm{d}}$ & 122 & 7 & $\begin{array}{c}4 / 92 a^{c} \\
5 / 92 a^{c}\end{array}$ & $\begin{array}{l}M \\
M\end{array}$ & 0,5 & 48,5 & - & - & Não adoeceu \\
\hline 15 & 60 & 2 & Controle & & & & & & \\
\hline 16 & 63 & 2 & Controle & & & & & & \\
\hline
\end{tabular}

centração de TMs na planta fêmea em floração do que nas plantas não em floração ou plantas macho em floração.

Dos bovinos que receberam a planta, 10 morreram ou foram sacrificados quando moribundos (Quadro 2). 0 tempo decorri- do entre a administração da planta e o início dos sinais clínicos foi semelhante em todos os casos e variou de 13 a 15 horas. A duração dos sinais clínicos variou de 2 a 35 horas, sendo no entanto maior no bovino 8 que recebeu uma única dose de $3 \mathrm{~g} /$

Quadro 3. Intoxicação experimental por Baccharis coridifolia (Compositae) em bovinos. Resultados da análise química por HPLC e GC-MS das amostras de Baccharis coridifolia

\begin{tabular}{|c|c|c|c|c|c|c|c|c|c|c|c|c|}
\hline \multirow{2}{*}{$\begin{array}{l}\text { Data da } \\
\text { coleta } \\
\text { (sexo da } \\
\text { planta) }\end{array}$} & \multicolumn{10}{|c|}{ Análise em HPLC para TMs } & \multicolumn{2}{|c|}{ Análise em Gc-Ms } \\
\hline & RA & RE & VA & VJ & $\mathrm{MC}$ & MF & $\begin{array}{l}\text { RA } \\
\text { sid }\end{array}$ & $\begin{array}{l}\text { RE } \\
\text { sid }\end{array}$ & $\begin{array}{l}\text { VA } \\
\text { sid }\end{array}$ & $\begin{array}{l}\text { MF } \\
\text { sid }\end{array}$ & Total & $\begin{array}{l}\text { Verru } \\
\text { carol }\end{array}$ \\
\hline $9 / 91 \quad(\mathrm{Nd})$ & & 165 & 215 & 50 & & 165 & 85 & 50 & & & 730 & 1320 \\
\hline $10 / 91(\mathrm{Nd})$ & & 65 & & 65 & & 215 & 200 & 210 & & & 755 & 1410 \\
\hline $11 / 91(\mathrm{Nd})$ & & 35 & 90 & 35 & 440 & 125 & 150 & 40 & & & 915 & 1550 \\
\hline $12 / 91(\mathrm{Nd})$ & & 90 & 105 & 50 & 360 & 125 & & 35 & & 20 & 785 & 730 \\
\hline $1 / 92 \quad(\mathrm{Nd})$ & & 50 & & 40 & 370 & 220 & & & & & 680 & 1500 \\
\hline 2/92a (M) & 15 & 5 & & 10 & 45 & 10 & & & & & 85 & 190 \\
\hline $2 / 92 b(F)$ & 375 & 740 & 260 & 300 & & & 1020 & 1300 & 165 & & 4160 & 3700 \\
\hline 3/92a (M) & 55 & 25 & & 20 & 125 & 115 & 80 & 20 & & & 440 & 720 \\
\hline $3 / 92 b(F)$ & 1000 & 1710 & 310 & 480 & & & 590 & 1680 & 80 & & 5850 & 9700 \\
\hline 4/92a (M) & & 20 & 30 & 10 & 170 & 80 & & & & & 310 & 1020 \\
\hline 4/92b (F) & & 75 & 50 & 40 & & & & & & & 165 & 480 \\
\hline 5/92a (M) & & 35 & 70 & 20 & & 100 & 45 & 30 & & & 300 & 630 \\
\hline $5 / 92 b(F)$ & & 65 & 120 & 60 & 230 & 200 & & & & & 675 & 890 \\
\hline 3/92a (M) & & & & 95 & & & & & & & 95 & 220 \\
\hline 3/92b (F) & 870 & 2060 & 670 & 750 & & & 1240 & 1430 & 280 & & 7300 & 8890 \\
\hline
\end{tabular}

${ }^{a}$ Abreviaturas usadas: HPLC $=$ cromotografia líquida em alta pressão, GC-MS = cromotografia de gás-espectofotometria de massa, $T M s=$ tricotecenos macrocíclicos, $\mathrm{RA}=$ roridina $\mathrm{A}, \mathrm{RE}=$ roridina $\mathrm{E}, \mathrm{VA}=$ verrucarina $\mathrm{A}, \mathrm{VJ}=$ verrucarina $\mathrm{J}, \mathrm{MC}=$ miotoxina $\mathrm{C}, \mathrm{MF}=$ miotoxina $\mathrm{F}$, sid $=$ glicosídeo, $\mathrm{Nd}=$ não determinado, $\mathrm{F}=$ fêmea, $\mathrm{M}=$ macho. Os números são em $\mathrm{mg} / \mathrm{g}$ de material da planta seca. 
kg da planta verde recém-colhida e morreu 95 horas após a administração. $O$ início dos sinais clínicos nesse bovino não foi observado. Estimou-se a duração dos sinais clínicos em 80 horas nesse animal, com base no tempo em que ocorria o início dos sinais clínicos nos outros bovinos.

Os sinais clínicos observados mais frequentemente (Quadro 4) consistiram nas fases iniciais de anorexia, tensão abdominal, sensibilidade à palpação na região abdominal, seguidos de gemidos e focinho seco. Os sinais progrediam para diarréia líqui$\mathrm{da}$, algumas vezes com sangue, atonia ruminal com aumento dos borbulhos contínuos e timpanismo leve. Os animais ficavam quietos, procurando não se movimentar muito e, quando o faziam, apresentavam instabilidade do trem posterior podendo andar com passadas curtas ou arrastando as pinças. Ocorria taquicardia e, em alguns casos, taquipnéia e leve sialorréia. Havia desidratação caracterizada por olhos no fundo das órbitas, perda da elasticidade da pele e emagrecimento progressivo com decúbito esternal, cabeça estirada para a frente ou virada em direção ao flanco e, ocasionalmente, alheamento ao meio ambiente. Por vezes, ocorria ranger de dentes, mioclonia nos músculos dos membros e da cabeça e decúbito lateral. Um dos animais (bovino $\mathrm{n}^{\circ}$ ) apresentou movimentos de pedalagem seguidos de morte.

Três bovinos (10, 12 e 14) que receberam a planta macho em floração, não adoeceram. Desses, um (bovino 10) recebeu $1,5 \mathrm{~g} / \mathrm{kg}$ da planta verde recém-colhida e outros dois (bovinos 12 e 14), receberam a planta dessecada em quantidade correspondente a $0,5 \mathrm{~g} / \mathrm{kg}$ da planta fresca recém-colhida, em peso. 0 outro animal que adoeceu mas sobreviveu (bovino 4 ), recebeu $2 \mathrm{~g} / \mathrm{kg}$ da planta verde recém-colhida em brotação. Os dois bovinos que receberam a planta fêmea ( 11 e 13) morrerram (Quadro 2).

Macroscopicamente, os principais órgãos afetados na intoxicação por $B$. coridifolia em bovinos foram os do tubo gastrintestinal (principalmente pré-estômagos) e os do sistema linfo-hematopoético. Nos pré-estômagos as lesões consistiram de desprendimento espontâneo do epitélio superficial do rúmen, deixando uma superfície avermelhada e que em alguns animais era mais acentuada nos sacos dorsal e ventral. Outras vezes a alteração consistia de atenuação ou ausência das vilosidades. Em dois bovinos (11 e 13) ocorreram lesões semelhantes (avermelhamento e edema) no retículo, mais acentuadamente próximo à prega retículo-ruminal. Ocorreu avermelhamento nas folhas do omaso nos bovinos 5 e 11. No abomaso foram vistos edema de submucosa. A mucosa estava difusamente vermelhoescura. Petéquias ou sufusões irregulares ocorriam, ocasionalmente, na região pilórica. Na região fúndica de dois animais (5 e 6) ocorreram petéquias e pequenas sufusões de $0,5 \mathrm{~cm}$ de diâmetro com distribuição multifocal.

No intestino delgado a intensidade e localização das lesões no duodeno, jejuno e íleo variaram de animal para animal. Alguns apresentaram mucosa difusamente avermelhada ou de aspecto hemorrágico e edemaciado e o conteúdo do intestino era líquido, abundante e de aspecto moderadamente sanguinolento. Em alguns casos havia petéquias e edema na mucosa do íleo e sufusões na mucosa do cólon espiral. Os linfonodos de todos os bovinos, com exceção do bovino 3, estavam vermelho- escuros e suculentos ao corte. Essa alteração era, na maioria das vezes, difusa ou, em alguns linfonodos, restrita à medular. Era mais acentuada nos linfonodos mesentéricos, bronquiais, intercostais, renais, ilíacos internos, mediastínicos e esplênicos. Em dois animais ( 5 e 6 ) havia petéquias no parênquima dos linfonodos mesentéricos. As placas de Peyer, na maioria dos bovinos, apresentavam-se salientes, edemaciadas, avermelhadas ou circundadas por hemorragia. Os acúmulos linfóides da válvula íleo-cecal estavam avermelhados ou com hemorragias ao longo dos seus bordos.

Microscopicamente, as alterações epiteliais dos pré-estômagos consistiram de necrose, caracterizada por acidofilia citoplasmática, cariopicnose, cariorrexia e cariólise, podendo afetar somente a camada basal, somente a espinhosa ou toda a espessura do revestimento epitelial (Fig. 1). Na maioria dos bovinos, a necrose atingia as três camadas do epitélio de revestimento, resultando em separação do epitélio próximo à lâmina basal com formação de extensas fendas. Em muitos casos, restos celulares podiam ser vistos no interior dessas fendas. Em alguns poucos animais as alterações necróticas apareciam como necrose individual de células da camada espinhosa. A necrose no epitélio dos pré-estômagos mostrou-se mais acentuada por ordem decrescente no saco cego caudal dorsal do rúmen, retículo, saco cego caudal ventral do rúmen, saco ventral do rúmen, saco dorsal do rúmen, pilar anterior do rúmen e omaso. As alterações do abomaso consistiram principalmente de edema e congestão da mucosa e submucosa. Discreto infiltrado de células mononucleares e alguns eosinófilos ocorriam na lâmina própria. Em dois animais as células parietais tinham o citoplasma bastante vacuolizado e havia necrose e descamação de células das fossetas, microabscessos e dilatação glandular. As lesões do duodeno e entrada íleo-cecal caracterizaram-se principalmente por necrose acentuada da mucosa. Necrose nos linfonodos (Fig. 2) foi um achado consistente. Os linfonodos mais afetados em ordem decrescente de frequência foram: $1^{\circ}$ ) pré-escapular, $2^{\circ}$ ) renal, bronquial, intercostal e mandibular, $3^{\circ}$ ) abdominal dorsal, ilíaco interno, mediastínico caudal, axilar e poplíteo, $4^{\circ}$ ) esplênico e mesentérico. A ordem decrescente de intensidade foi: $1^{\circ}$ ) esplênico, $2^{\circ}$ ) renal, $3^{\circ}$ ) mandibular, $4^{\circ}$ ) bronquial e mediastínico caudal, $5^{\circ}$ ) abdominal dorsal, $6^{\circ}$ ) axilar, $7^{\circ}$ ) ilíaco interno, $8^{\circ}$ ) intercostal, $9^{\circ}$ ) mesentérico, $10^{\circ}$ ) pré-escapular e $11^{\circ}$ ) poplíteo. A necrose envolvia todas as regiões dos linfonodos, ocorrendo em forma decrescente de intensidade no folículo secundário, folículo primário e na região paracortical. As alterações no seio subcapsular caracterizavam-se por dilatação e conteúdo de detritos necróticos; quando acentuadas envolviam o folículo. A necrose era caracterizada pela presença de células com citoplasma eosinofílico e núcleo picnótico ou em cariorrexia. Essa alteração produzia áreas vazias ou contendo restos celulares. Outras alterações foram dilatação acentuada dos seios linfáticos que eram preenchidos por material homogêneo fortemente eosinofílico. Essa alteração era localizada ou difusa. Muitos linfonodos apresentavam histiocitose sinusal, mais frequentemente na medular mas, ocasionalmente atingindo a cortical e os seios subcapsulares.

No bovino 7, que recebeu quatro doses diárias de $0,5 \mathrm{~g} /$ $\mathrm{kg}$ da planta seca (equivalente a $1 \mathrm{~g} / \mathrm{kg}$ da planta verde por dia 
Quadro 4. Intoxicação experimental por Baccharis coridifolia (Compositae) em bovinos . Principais sinais clínicos

\begin{tabular}{|c|c|c|c|c|c|c|c|c|c|}
\hline \multirow[t]{2}{*}{$\begin{array}{c}\text { Bovino } \\
\mathrm{n}^{\text {oa }}\end{array}$} & \multicolumn{9}{|c|}{ Sinais clínicos } \\
\hline & Anorexia & $\begin{array}{l}\text { Atonia } \\
\text { ruminal }\end{array}$ & Dor & $\begin{array}{c}\text { Tensão } \\
\text { abdominal }\end{array}$ & $\begin{array}{l}\text { Diarréia } \\
\text { líquida }\end{array}$ & $\begin{array}{l}\text { Focinho } \\
\text { seco }\end{array}$ & $\begin{array}{c}\text { Instabilidade } \\
\text { do trem } \\
\text { posterior }\end{array}$ & $\begin{array}{c}\text { Decúbito } \\
\text { esternal }\end{array}$ & Desidratação \\
\hline 01 & + & + & + & + & $+^{c}$ & + & + & + & + \\
\hline 02 & + & + & + & + & + & + & + & + & + \\
\hline 03 & + & + & + & - & + & + & - & + & + \\
\hline $04^{\mathrm{b}}$ & + & + & + & + & + & + & + & - & + \\
\hline 05 & + & + & + & + & + & + & + & + & + \\
\hline 06 & + & + & + & + & + & + & - & + & + \\
\hline 07 & + & + & + & + & + & + & + & + & + \\
\hline 08 & + & + & + & + & - & - & - & + & + \\
\hline 09 & + & + & + & + & $+^{c}$ & + & + & + & + \\
\hline 13 & + & + & + & + & + & + & - & + & + \\
\hline
\end{tabular}

aOs sinais clínicos do bovino $\mathrm{n}^{\circ} 11$ não foram acompanhados. Os bovinos $\mathrm{n}^{\circ} 10,12$ e 14 não adoeceram; bobreviveu; 'Diarréia com estrias de sangue.

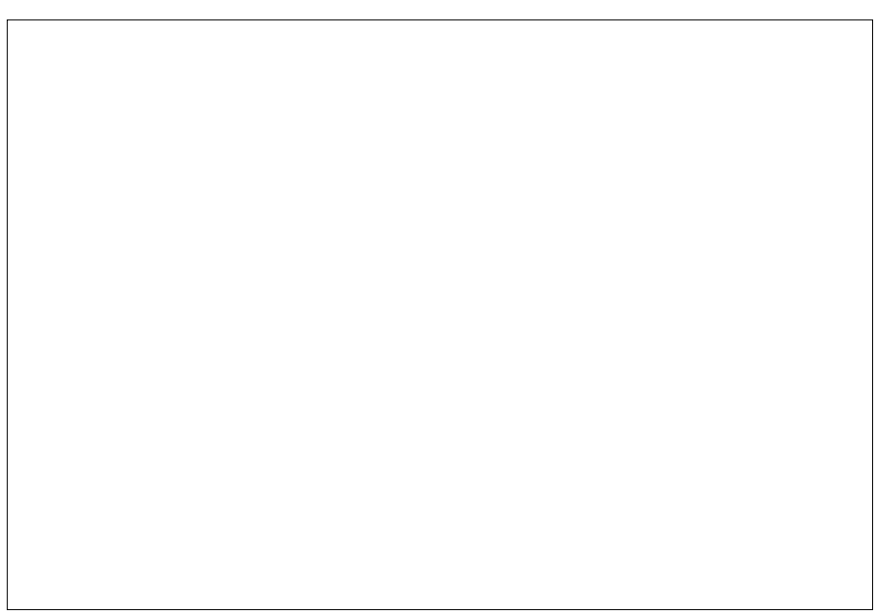

Fig. 1. Necrose do epitélio ruminal, na intoxicação por Baccharis coridifolia (Bovino 11). HE, obj. 16.

em termos de toxidez) em fase de brotação, as alterações necróticas nos linfonodos foram discretas ou inexistentes. Necrose linfóide foi também observada no baço, nas placas de Peyer, nos acúmulos linfóides da submucosa do duodeno e entrada íleo-cecal. Não se observaram alterações no timo.

\section{DISCUSSÃO}

Busam \& Habermehl (1982), relataram, pela primeira vez, o isolamento dos Tricotecenos macrocíclícos (TMs) roridina A e E de $B$. coridifolia. Os altos níveis dessas potentes micotoxinas são responsáveis pela toxicidade da planta para bovinos (Tokarnia \& Döbereiner 1975), ovinos (Tokarnia \& Döbereiner 1976), coelhos (Döbereiner et al. 1976, Rodrigues \& Tokarnia 1995) e equinos (Costa et al. 1995). Poucos estudos, no entanto, compararam a toxicidade de espécimes machos e fêmeas de $B$. coridifolia. Em um estudo da intoxicação experimental em coelhos (Rodrigues et al. 1995), a planta fêmea mostrou-se até 32 vezes

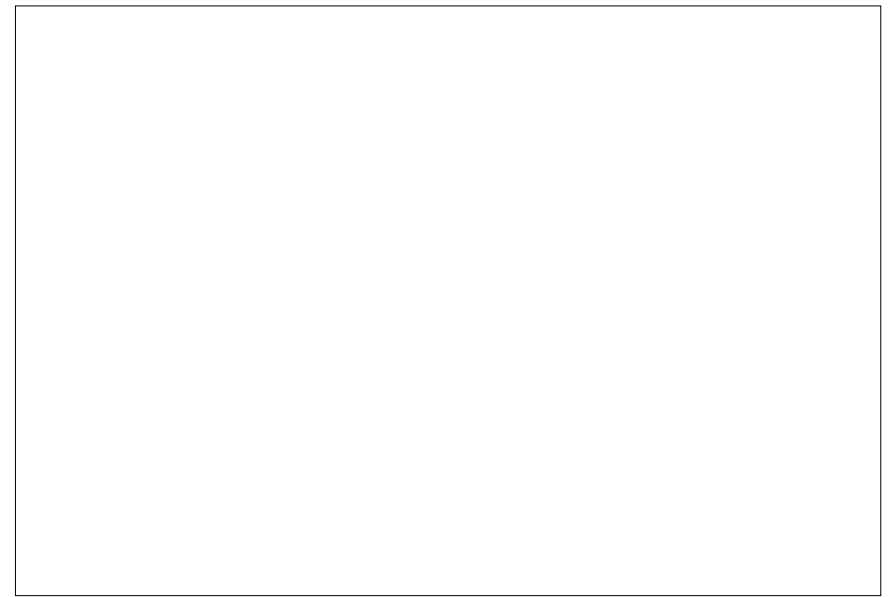

Fig. 2. Necrose de linfócitos do folículo linfóide em linfonodo mesentérico, na intoxicação experimental por B. coridifolia (Bovino 5). HE, obj. 16.

mais tóxica do que a planta macho. Essa relação entre a toxicidade e o sexo da planta já havia sido demonstrada com base em análises químicas (Jarvis et al. 1988). Os resultados deste estudo confirmam esses achados, isto é, há uma notável diferença nos níveis de TMs e seus glicosídeos na planta fêmea quando comparada com esses níveis nas plantas que não estão em floração e com o das plantas macho em floração. A concentração de TMs aumenta substancialmente quando a planta fêmea entra em floração. Como se pode constatar, esse aumento ocorre rapidamente: os níveis de TMs em plantas não em floração foram menores que 1.000 ppm. Já as plantas fêmeas colhidas no início do período de floração (2/92b, 3/92b e 3/93b) apresentaram concentrações maiores que $4.000 \mathrm{ppm}$.

Os resultados das análise químicas têm, em geral, correlação com os resultados obtidos com a administração da planta aos bovinos (Quadro 4), embora uma análise quantitativa precisa dos dados toxicológicos não possa ser feita devido ao pequeno 
número de animais usados. $\mathrm{O}$ bovino 4 que recebeu $2 \mathrm{~g} / \mathrm{kg}$ da colheita de planta 9/91, ficou doente, mas se recuperou completamente. Bovinos que receberam $3 \mathrm{~g} / \mathrm{kg}$, respectivamente das colheitas de planta 10/91 e 12/91, morreram após 48 e 95 horas e o bovino 6 que recebeu $3 \mathrm{~g} / \mathrm{kg}$ da colheita $11 / 91 \mathrm{morreu}$ após 16 horas. Bovinos que receberam $0,5 \mathrm{~g} / \mathrm{kg}$ da planta macho coIhida em abril e maio de 1992, não adoeceram. Dados mais contundentes são os relacionados com a administração da planta colhida em março de 1992. Dois bovinos (ambos com 90kg) receberam a planta dessa colheita numa única dose de $1,5 \mathrm{~g} / \mathrm{kg}$; o bovino que recebeu a planta macho não adoeceu, ao passo que o bovino que recebeu a planta fêmea morreu 12 horas após a administração.

Há um dado conflitante nos resultados da análise química da planta. A amostra 4/92b, fêmea, apresentou uma quantidade menor de tricotecenos macrocíclicos (165) do que a amostra 4/ 92a, macho (310). A amostra 4/92a (macho) foi administrada ao bovino 12, o qual sobreviveu sem apresentar sinais clínicos. No entanto, essa amostra 4/92b (fêmea) não foi administrada aos bovinos e sua toxidez não pôde ser comprovada. É possível que alguma dificuldade técnica na análise química tenha contribuído para essa discrepância.

Os sinais clínicos observados foram semelhantes aos descritos anteriormente para a intoxicação em bovinos (Tokarnia \& Döbereiner 1975, Barros 1993). Em estudos anteriores com a intoxicação experimental por B. coridifolia em bovinos (Tokarnia \& Döbereiner 1975), a diarréia foi um sinal clínico marcante em animais que adoeceram e se recuperaram. Isso sugeria um bom prognóstico para os casos em que a diarréia estivesse presente. Os nossos dados não confirmam essas observações: dos bovinos que morreram neste experimento, apenas um não apresentou diarréia.

Sinais clínicos de distúrbios nervosos são relatados na intoxicação por B. coridifolia em bovinos (Tokarnia \& Döbereiner 1975), ovinos ( Tokarnia \& Döbereiner 1976) e equinos (Costa et al. 1995). Em bovinos (Tokarnia \& Döbereiner 1975), são mencionados instabilidade dos membros posteriores, tremores musculares e inquietação. Em equinos ocorreram protusão da língua, midríase, nistagmo, instabilidade locomotora e andar em círculos (Costa et al. 1995). Nos animais desse experimento, alguns sinais clínicos como inquietação, instabilidade nos membros posteriores, tremores musculares, ranger de dentes e movimentos de pedalagem, podem ser interpretados como sendo de distúrbios nervosos. Nos segmentos de encéfalo examinados por técnica histológica de rotina, no entanto, não foram encontradas alterações morfológicas que justificassem os sinais clínicos. A explicação para os sinais clínicos acima descritos reside, então, em duas alternativas: existem lesões no sistema nervoso central que não podem ser detectadas pelos exames de rotina empregados aqui ou esses sinais clínicos são provocados pela dor ou por outros efeitos da planta que não no sistema nervoso central.

As lesões mais importantes verificadas nos bovinos intoxicados experimentalmente por $B$. coridifolia localizaram-se no sistema digestivo, principalmente nos pré-estômagos e são muito semelhantes às descritas anteriormente (Tokarnia \& Döbereiner 1975, Barros 1993). Neste estudo foi possível determinar as regiões dos pré-estômagos afetadas mais intensamente. Dados como esses podem ser úteis na seleção de fragmentos para exa- me histológico, uma vez que as lesões à necropsia nem sempre são bem definidas macroscopicamente.

As lesões necróticas dos linfonodos como as vistas nos bovinos desse experimento não são descritas, pela maioria dos outros autores, em associação com a intoxicação por $B$. coridifolia e, embora tenham sido já mencionadas na intoxicação em bovinos (Barros 1993), não tinham ainda sido objeto de estudo sistemático como o que foi realizado aqui. Lesões semelhantes, embora mais intensas, são descritas em tecidos linfóides de bovinos intoxicados por B. megapotamica (Tokarnia et al. 1992). A distribuição das lesões dentro de um mesmo linfonodo e entre 12 linfonodos e vários acúmulos linfóides foi determinada. $\mathrm{O}$ conhecimento dos linfonodos mais frequentemente afetados pode auxiliar na decisão de quais linfonodos colher à necropsia para o exame histológico.

Em nenhum caso observou-se necrose dos linfócitos do timo. Isso, associado à distribuição das lesões dentro dos linfonodos, sugere que as células afetadas sejam linfócitos B. A ação de TMs sobre os linfócitos $\mathrm{B}$ já foi documentada no tratamento de ratos com leucemia tipo B (Kupchan et al. 1977).

\section{REFERÊNCIAS}

Busam L. \& Habermehl G.G. 1982. Accumulation of mycotoxins by Baccharis coridifolia: a reason for livestock poisoning. Naturwissenschaften 69:391393.

Barros C.S.L. 1993. Intoxicações por plantas que afetam o tubo digestivo, p. 159-169. In: Riet-Correa F., Méndez M.C. \& Schild A.L. (ed.) Intoxicação por Plantas e Micotoxicoses em Animais Domésticos. Editorial Hemisfério Sul do Brasil, Pelotas. 340 p.

Costa E.R., Costa J.N., Armién A.G., Barbosa J.D. \& Peixoto P.V. 1995. Intoxicação experimental por Baccharis coridifolia (Compositae) em equinos. Pesq. Vet. Bras. 15:19-26.

Döbereiner M.L., Rezende A.M.L. \& Tokarnia C.H. 1976. Intoxicação experimental por Baccharis coridifolia em coelhos. Peq. Agropec. Bras., Ser. Vet. 11:27- 35.

Jarvis B.B., Midiwo J.O., Bean G.A., Abdoul Nasr M.B. \& Barros C.S. 1988. The mystery of trichothecene antibiotics in Baccharis species. J. Nat. Prod. 4:736-744.

Jarvis B.B., Wang S., Cox C., Philip V., Varaschin M.S. \& Barros C.S. 1996. Brazilian Baccharis toxins: Livestock poisoning and isolation of macrocyclic trichothecenes glucosides. Nat. Toxins 4:58-71.

Kupchan S. M., Steelman D. R., Jarvis B.B., Dailey R.G. \& Seneden A.T. 1977. Isolation of potent new antileukemic trichothecenes from Baccharis megapotamica. J. Org. Chem. 42:4221-4225.

Méndez M.C. 1995. Comunicação pessoal (Laboratório Regional de Diagnóstico, Faculadade de Veterinária, Universidade Federal de Pelotas, Pelotas, RS).

Occhioni P. 1944. Contribuição ao estudo do “mio-mio", Baccharis coridifolia D. C. Bolm Soc. Bras. Med. Vet. 13:193-209.

Rodrigues R.L. \& Tokarnia C.H. 1995. Fatores que influenciam a toxidez de Baccharis coridifolia (Compositae): um estudo experimental em coelhos. Pesq. Vet. Bras. 15:51-69.

Tokarnia C. H. \& Döbereiner J. 1975. Intoxicação experimental em bovinos por "mio-mio", Baccharis coridifolia. Pesq. Agropec. Bras., Sér. Vet. 10:7997.

Tokarnia C.H. \& Döbereiner J. 1976. Intoxicação experimental em ovinos por "mio-mio", Baccharis coridifolia. Pesq. Agropec. Bras., Sér. Vet. 11:1926.

Tokarnia C.H., Peixoto P.V., Gava A, Barros C.S.L.1992. Intoxicação experimental por Baccharis megapotamica var. megapotamica e var. weirii (Compositae) em bovinos. Pesq. Vet. Bras. 12:19-31. 